\title{
Prospective Study Comparing Skin Impedance with EEG Parameters during the Induction of ANAESTHESia with FENTANYL AND ETOMIDATE
}

\author{
M. Winterhalter ${ }^{1}$, S. Münte ${ }^{4}$, M. Gerhard ${ }^{3}$, O. Danzeisen ${ }^{1}$, T. Jüttner ${ }^{1}$, E. Monaca ${ }^{1}$, L. Hoy², \\ N. Rahe-Meyer ${ }^{3}$, P. Kienbaum ${ }^{1}$ \\ ${ }^{1}$ Department of Anaesthesiology, University of Düsseldorf, Germany, \\ ${ }^{2}$ Department of Biometry, Hannover Medical School, Germany, \\ ${ }^{3}$ Department of Anaesthesiology, Hannover Medical School, Germany, \\ ${ }^{4}$ Department of Anaesthesiology, Helsinki University Clinics, Hospital for Children and Adolescent, Finland
}

\begin{abstract}
Objective: Sympathetic stimulation leads to a change in electrical skin impedance. So far it is unclear whether this effect can be used to measure the effects of anaesthetics during general anaesthesia. The aim of this prospective study is to determine the electrical skin impedance during induction of anaesthesia for coronary artery bypass surgery with fentanyl and etomidate.

Methods: The electrical skin impedance was measured with the help of an electro-sympathicograph (ESG). In 47 patients scheduled for elective cardiac surgery, anaesthesia was induced with intravenous fentanyl 10 $\mu \mathrm{g} / \mathrm{kg}$ and etomidate $0.3 \mathrm{mg} / \mathrm{kg}$. During induction, the ESG (Electrosympathicograph), BIS (Bispectral IndeX), BP (arterial blood pressure) and HR (heart rate) values of each patient were recorded every $20 \mathrm{sec}-$ onds. The observation period from administration of fentanyl to intubation for surgery lasted $4 \mathrm{~min}$.

Results: The ESG recorded significant changes in the electrical skin impedance after administration of fentanyl and etomidate $(\mathrm{p}<0.05)$. During induction of anaesthesia, significant changes of BIS, HR and blood pressure were observed as well $(\mathrm{p}<0.05)$.

Conclusions: The electrical skin impedance measurement may be used to monitor the effects of anesthetics during general anaesthesia.
\end{abstract}

Key words: skin impedance, general anaesthesia, fentanyl, etomidate, cardiac surgery

\section{INTRODUCTION}

Clinical assessment uses parameters such as heart rate and blood pressure to determine anaesthetic depth. Administration of etomidate in combination with fentanyl has been suggested for induction of anaesthesia in high-risk patients for cardiac surgery, because of their minor cardiovascular effects [1]. The partly opposed effects of etomidate and fentanyl on heart rate and blood pressure do not allow to predict the adequacy of anaesthesia on the basis of these parameters [2,
3, 4]. This is particularly the case in cardiac high-risk patients, whose heart rate and blood pressure behaviour are often dictated by the underlying heart impairment and by heart medication. Cardiosurgical operations are considered to bear a higher risk of unintended intraoperative awareness compared to general surgical operations [5].

A previous study addressing EEG changes during a cardiosurgical operation with postoperative recall found no relationship between the time spent awake and EEG changes [6]. In addition, Barr and colleagues observed an insufficient correlation between bispectral index and intraoperatively measured plasma midazolam and fentanyl levels and clinical assessment of anaesthetic depth in 10 cardiosurgical patients [7]. In a study targeting the induction of anaesthesia using fentanyl in cardiosurgical patients, the same authors came to the conclusion that the BIS monitor is not capable to measure the hypnotic effects of fentanyl [8].

In a further study dealing with assessing anaesthetic depth by means of skin conductance measurements, the state of activity of the sympathetic nerve system was predicted with the help of the eccrine sweat gland duct filling. For this purpose, the authors measured the changes in a parameter called NSCF (number of skin conductance fluctuations). This parameter that correlates directly with bursts in the skin sympathetic nervous system was suggested to be an indicator of the analgesic effects of opioids during general anaesthesia [9].

Opiates, just like narcotics, act through central mechanisms thereby damping the activity of the sympathetic system, followed by changes in skin impedance. The aim of the present prospective study was to investigate the effects upon skin impedance of an intravenous bolus of fentanyl, which was given without previous administration of hypnotics, and a subsequent etomidate bolus.

For this purpose, the electrosympathicograph (ESG) was used to measure the changes in skin impedance in patients undergoing elective cardiac surgery. 


\section{METHODS}

\section{PATIENTS}

47 patients (ASA III), who were undergoing elective cardiosurgical intervention, were studied prospectively. Approval for the study was given by the local Medical Ethics Committee. All patients gave their written informed consent prior to being enrolled into the study.

Patients aged under $18 \mathrm{yr}$ were excluded, as were those with neurologic or psychiatric diseases, intake of psychoactive mediation, abuse of drugs or alcohol,,skull-brain trauma in the patient's medical history, and hearing disorders.

Table 1. Participants characteristics.

\begin{tabular}{ll}
\hline Gender (Male/Female), (n) & $34 / 13$ \\
ASA III (n,\%) & 47,100 \\
Age (yr) & $59 \pm 17$ \\
Height (cm) & $170 \pm 27$ \\
Weight (kg) & $79 \pm 18$ \\
\hline
\end{tabular}

Data shown as mean \pm SD unless otherwise indicated

\section{Study and Test Procedures}

All study measurements were carried out in an anaesthesia induction room patients laying on supine on an operation table. Prior to induction of anaesthesia, an invasive blood pressure measurement system via the arteria radialis was established, a venous catheter and a pulse oximeter were placed and an ECG (electrocardiogram) was administered. The invasively measured blood pressure and heart rate were stored directly online in a computer file with the assistance of the program AS3 collect (Datex-Ohmeda S/5 Anaesthesia Monitor System). All study participants were continuously administered 4 liters of $\mathrm{O}_{2}$ through a nasal probe. A BIS electrode (BIS Sensor XP) for BIS monitoring was attached to the forehead in accordance with the specifications from the manufacturer. As for ESG monitoring, 2 ECG electrodes were fastened to the palm ( $2^{\text {nd }}$ and $3^{\text {rd }}$ finger $)$ of the non-dominating hand. The timers of the S/5 Anaesthesia Monitor System, BIS Monitor and ESG were synchronised prior to beginning the measurements. A serial cable was connected to both the BIS monitor and a laptop in order to enable continuous recording of the BIS values; the laptop stored the data in a text file with the help of the Microsoft Hyperterminal program. The ESG used a continuous real-time automatic online process to store the measured skin impedance data in a computer file over the entire period of time.

At the beginning of the observation period, baseline measurements of ESG, BIS, BP and HR values were recorded. Thereafter, the patients received 1.0 $\mu \mathrm{g} / \mathrm{kg}$ intravenous fentanyl. 160 seconds after administration of fentanyl, the patients were injected with additional $0.3 \mathrm{mg} / \mathrm{kg}$ of etomidate. After the loss of eyelash reflex, patients were ventilated through an oxygen mask and pancuronium $0.1 \mathrm{mg} / \mathrm{kg}$ was given to facilitate tracheal intubation. The study period lasted from the time of administration of fentanyl up to the time of intubation (approximately four minutes).

\section{ESG AND BIS MEASUREMENTS}

Skin impedance measurements were performed with the help of an electrosympathicograph (ESG) (ESG 1001 Monitor System, Dr. Janitzki Consulting Engineers, Altenbeken, Germany). The measurement was made in the constant direct current mode with the help of $\mathrm{Ag} / \mathrm{AGCl}$ electrodes that were applied to a small skin area at a current density of $<2 \mu \mathrm{A} / \mathrm{cm}^{2}$. Every $200 \mathrm{~ms}$ (5 HZ), the impedance data were periodically recorded in real time [10], underwent analog signal processing and filtering, and were then transmitted to an analog-to-digital converter. The very large measurement range demanded that an analog-to-digital converter having a resolution of 18 bits plus sign be used. In order to not leave the measurement data susceptible to failure, digitization was done as soon as possible. Opto-couplers then transferred the digital data to a computer for further processing.

This computer predominantly fulfills three tasks: it organizes and controls the recording of the measurement data (likewise via optocouplers), performs the digital processing of the recorded measurement data and displays them on a monitor screen. Thirdly, the computer performs a quasi-continuous recording (every 0.2 seconds) of all digital measurement data in a non-volatile storage medium (storage space requirements: ca. 100 KByte per hour and channel). The data so stored can be exactly assigned to each single measurement and to a specific time, which allows them to be used by other computers and programs in a later processing.

The system's measurement range spans from 5000 $\Omega$ to $2,000,000 \Omega$. It is also possible to perform measurements below $5000 \Omega$, but then the measurement sensitivity is strongly reduced, and the temperature dependence of the sensors increases. Changes of up to $100 \Omega$ are in the normal sensitivity range. The baseline impedance values on the insides of the hands are in the range from $10,000 \Omega$ up to several $100,000 \Omega$.

Available skin impedance recording electrodes included standard ECG solid gel surface electrodes having a recording surface of $2.2 \mathrm{~cm}^{2}$, and consisting of a $5 \% \mathrm{KCl}$ conductive adhesive gel (Conmed - 1700 Cleartrace; Conmed Deutschland GmbH, Gross-Gerau, Germany).

The skin impedance monitor (ESG) records 5 measurement values per second. While the measurements are being made, the measurement data appear graphically on the monitor screen in the form of a tonic electrosympathicogram (tonic ESG) in a time function as ESG measurement curve expressed in $\mathrm{K} \Omega$ (Kilo $\mathrm{Ohm}$ ). These measurement values appear online in a diagram directly on the monitor screen without having undergone additional pre-processing. The tonic ESG measurement value in $K \Omega$ is updated every 5 seconds and shown in a numeric display. The method was recently published $[11,12]$.

For determination by bispectral analysis we used an A- 2000 BIS monitor (software version 3.3, Aspect Medical Systems, Newton, MA, USA). Every five sec- 
onds the Aspect 2000 BIS monitor delivers a new bispectral analysis, which is calculated retroactively from the past 15 seconds. For us to be able to do a statistical evaluation, BIS, ESG, blood pressure and heart rate values were taken every 20 seconds from the time of administration of fentanyl up to the time of intubation. Two investigators read all measurement values directly from the monitor screen and entered them into a previously developed test protocol. Prior to statistical analysis, all values entered by hand were examined for accuracy; this was achieved by comparing them to the values recorded online.

\section{STATISTICAL ANALYSIS}

The statistical evaluation served the purpose of identifying possible correlations between skin impedance data and time and BIS values.

Possible temporal changes in ESG values were identified using the multivariate analysis of repeated measurements, a specific analysis method for time-dependent data. The time-dependent effect was quantified using Wilks' Lambda.

In addition to the absolute ESG values, any changes in the ESG values compared to the baseline value were also determined using the following two formulae: $\operatorname{RESG}\left(\mathrm{t}_{\mathrm{x}}\right)=\left[\operatorname{ESG}\left(\mathrm{t}_{\mathrm{x}}\right)-\operatorname{ESG}\left(\mathrm{t}_{0}\right)\right]$./ $\operatorname{ESG}\left(\mathrm{t}_{0}\right)$. And $\operatorname{DESG}\left(\mathrm{t}_{\mathrm{x}}\right)=\operatorname{ESG}\left(\mathrm{t}_{\mathrm{x}}\right)-\operatorname{ESG}\left(\mathrm{t}_{0}\right)$

$\left[\operatorname{RESG}\left(t_{\mathrm{x}}\right)=\right.$ relative change in ESG at the time of measurement; $\mathrm{ESG}\left(\mathrm{t}_{\mathrm{X}}\right)=\mathrm{ESG}$ at the time of measurement; $\mathrm{ESG}\left(\mathrm{t}_{0}\right)=\mathrm{ESG}$ at baseline time point; $\operatorname{DESG}\left(\mathrm{t}_{\mathrm{x}}\right)$ $=$ change in ESG at the measurement time point].

This enables to look only at the course of the ESG values, independently of different absolute values.

The paired t-test compared the parameters (BIS, ESG) during their time course after administration of fentanyl and etomidate. Another operation that was done included computing Pearson's correlation coefficients between BIS and ESG values at the individual measurement time points.

A value of $p<0.05$ was considered statistically significant. Statistical evaluation was done with the assistance of the SPSS program for Windows, version 14.0 (SPSS Inc, Chicago, Illinois, USA).

\section{RESULTS}

Relevant complications were not observed in any study participant. During the observation period, no patient experienced a decrease in peripheral saturation below 90. All 47 patients were intubated and mechanically ventilated at the end of the observation period. Thereafter, the surgical intervention was performed as planned. The observation period lasted $280 \mathrm{~s}$ for each patient

160 seconds after fentanyl administration, the heart rate had fallen significantly from $75 \pm 15$ to $70 \pm 16$ $1 / \min (p=0.04)$. Administration of etomidate produced a significant rise in heart rate within 120 seconds, namely from $70 \pm 16$ to $74 \pm 191 / \mathrm{min}(\mathrm{p}=$ 0.0001). (Fig. 1). At the time of intubation, the heart rate showed another rise to $77 \pm 201 / \mathrm{min} .160 \mathrm{sec}-$ onds after the administration of fentanyl, the mean blood pressure had fallen significantly from $96 \pm 19$ to $86 \pm 23 \mathrm{mmHg}(\mathrm{p}=0.009)$. A significant change in

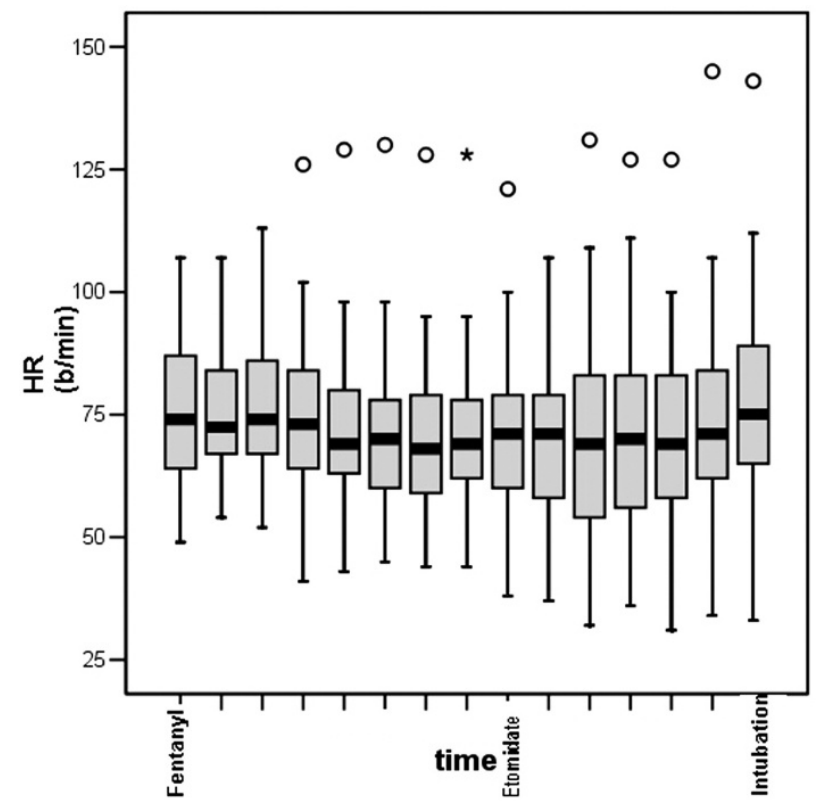

Fig. 1. HR during induction of Anaesthesia. Boxes indicate median and $24^{\text {th }}-75^{\text {th }}$ percentiles, whiskers the range.

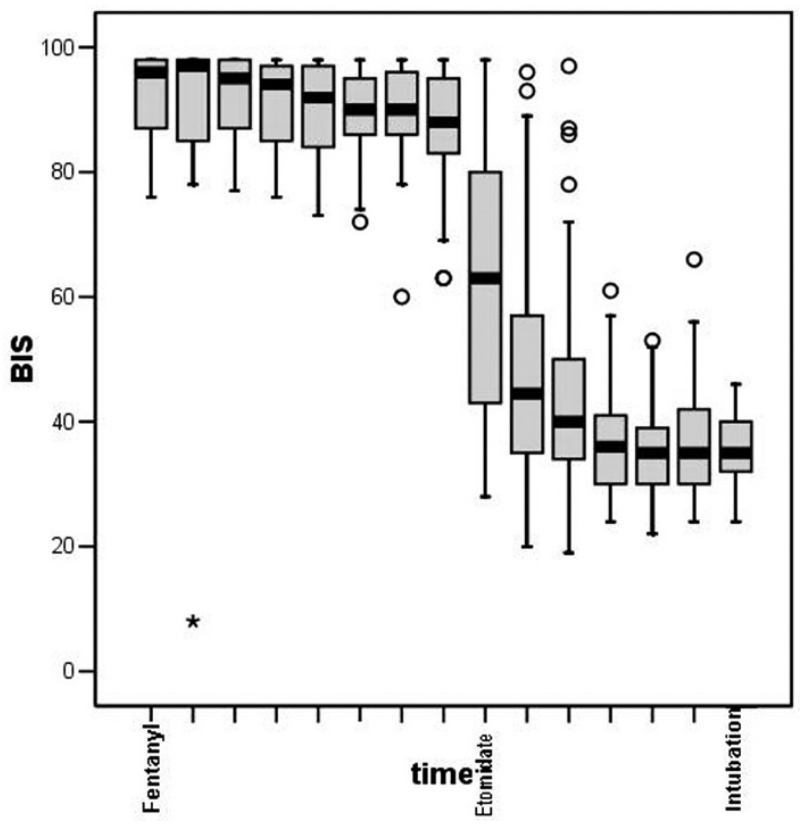

Fig. 2. BIS index during induction of Anaesthesia. Boxes indicate median and $24^{\text {th }}-75^{\text {th }}$ percentiles, whiskers the range.

blood pressure was also observed after administration of etomidate. At first, mean blood pressure fell from $86 \pm 19$ to $77 \pm 18$, and then it rose to be $87 \pm 23$ at the time of intubation $(p=0.005)$. This elevation in blood pressure was caused by an early administration of noradrenaline in order to maintain sufficient coronary perfusion pressure.

Following administration of fentanyl, the bispectral index changed significantly from $93 \pm 6$ to $87 \pm 10(\mathrm{p}$ $=0.036$ ). During the time that elapsed from etomidate administration until intubation, the bispectral index value fell highly significantly from $62 \pm 21$ to $36 \pm 6$ $(\mathrm{p}<0.001)$ (Fig. 2). Administration of fentanyl also 


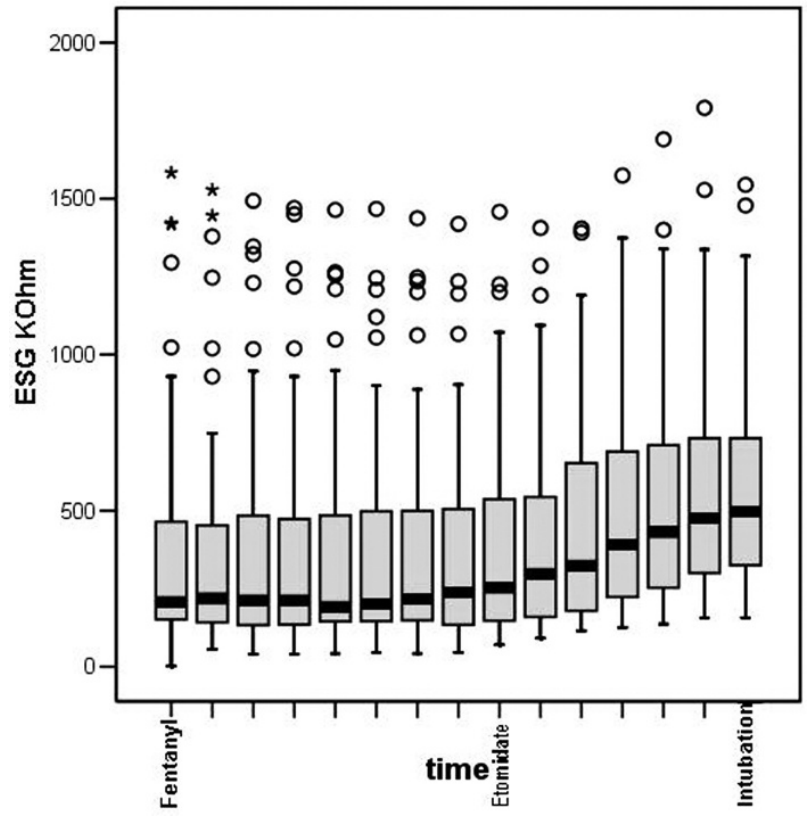

Fig. 3. ESG during induction of Anaesthesia. Boxes indicate median and $24^{\text {th }}-75^{\text {th }}$ percentiles, whiskers the range.

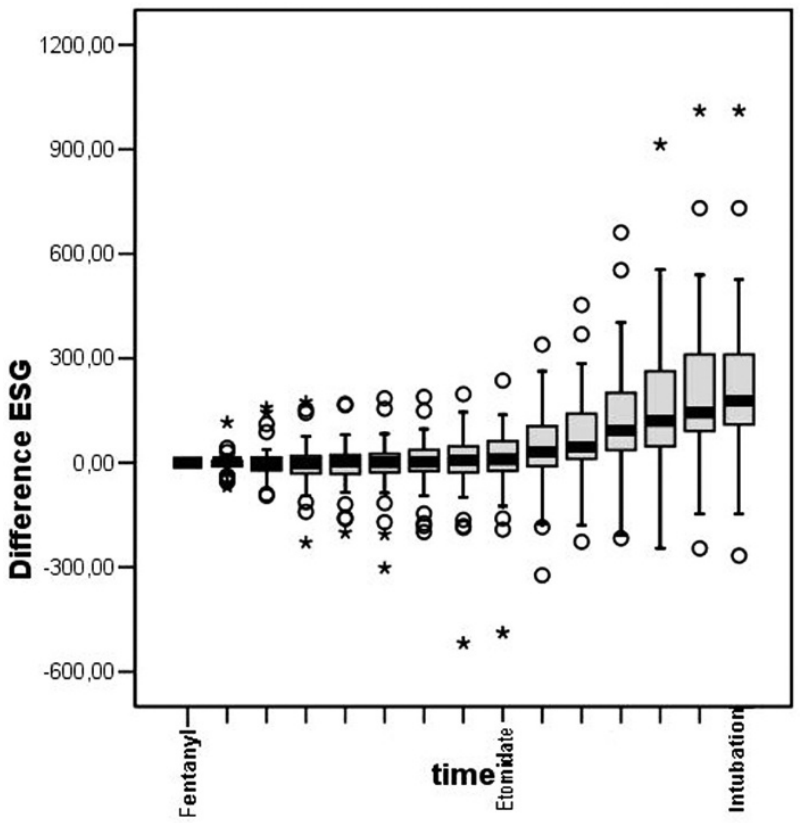

Fig. 4. Difference ESG during induction of Anaesthesia. Boxes indicate median and $24^{\text {th }}-75^{\text {th }}$ percentiles, whiskers the range.

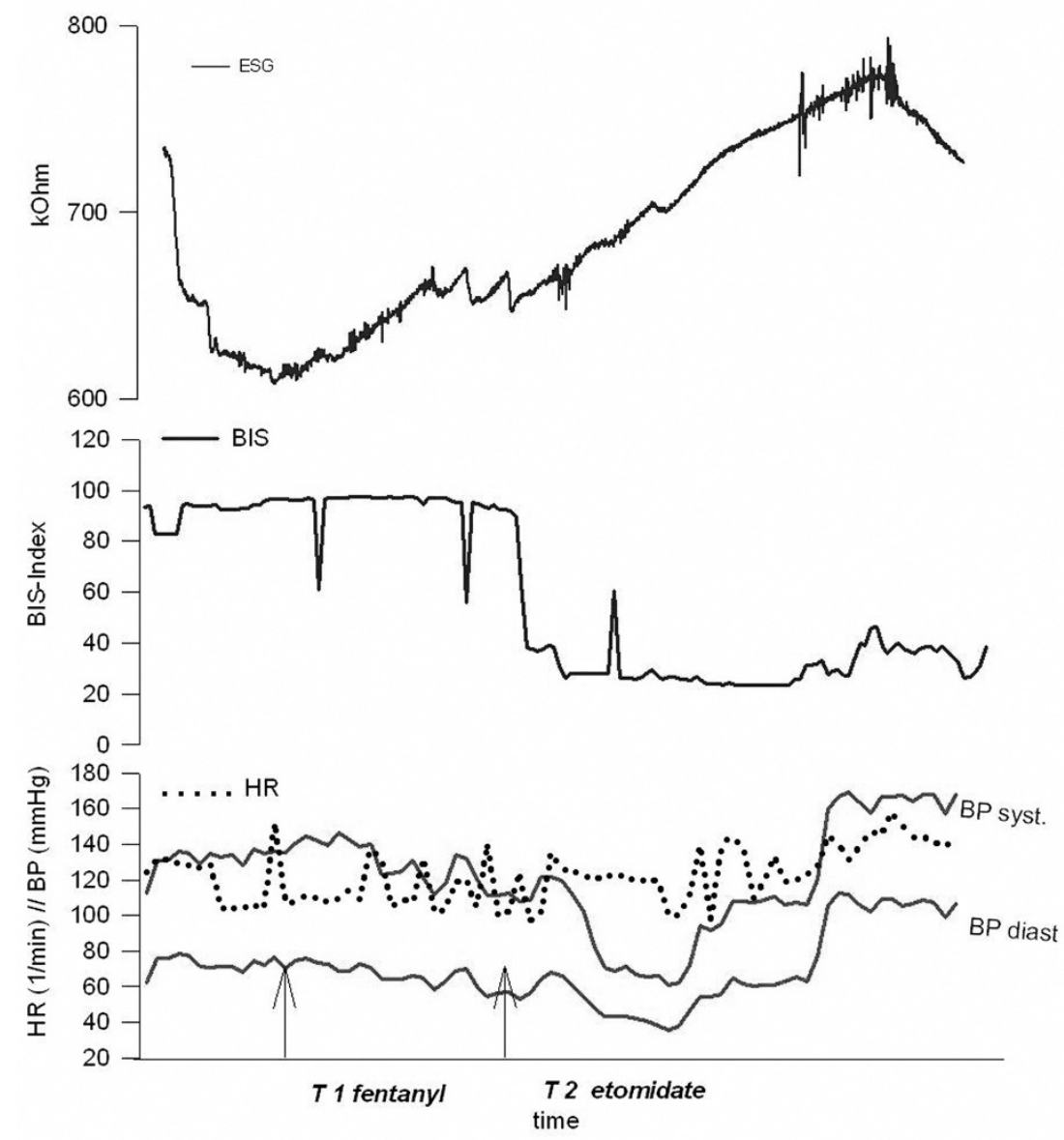

Fig. 5. Original curves of a patient during induction of Anaesthesia.

produced a significant change in spectral edge frequency, namely from $20 \pm 7$ to $18 \pm 6$ ( $p=0.03$ ). After etomidate injection, it fell highly significantly to 14 $\pm 2(\mathrm{p}=0.0001)$.

Within 160 seconds after administration of fentanyl, the skin impedances measured by the ESG exhibited a broad spread due to the high degree of variance between the baseline values. The average values fluctuated from $378 \pm 441 \mathrm{k} \Omega$ at the time of the injection of fentanyl, to $374 \pm 348 \mathrm{k} \Omega 160$ seconds after the injection (Fig. 3) That is why also the changes in ESG values with respect to the baseline values were looked at 
in addition to the absolute ESG values. After injection of fentanyl, there was a significant change in the relative difference of the ESG values (RESG $\left.t_{\mathrm{x}}\right)$ ) from $2.5 \pm 17$ to $3.3 \pm 22$ ( $\mathrm{p}=0,021)$. After injection of etomidate, the course of the (RESG $\left.t_{x}\right)$ ) values demonstrated a highly significant change from $3.1 \pm 20$ to $17 \pm 107$ (Fig. 4). Even the absolute ESG values exhibited a highly significant change after infusion of etomidate; despite their broad spread they fluctuated from $388 \pm 345 \mathrm{k} \Omega$ to $595 \pm 361 \mathrm{k} \Omega .(\mathrm{p}=0.0001)$ (Fig. 3).

Pearson's Correlation at the individual measurement time points measured a significant (negative) correlation relationship between the absolute ESG values and BIS values at the beginning $(\mathrm{r}=-0,3 ; \mathrm{p}=0.04)$, $40 \mathrm{~s}(\mathrm{r}=-0,4 ; \mathrm{p}=0.005), 60 \mathrm{~s}(\mathrm{r}=-0,3 ; \mathrm{p}=0.02), 80 \mathrm{~s}$ $(\mathrm{r}=-0,3 ; \mathrm{p}=0.04), 100 \mathrm{~s}(\mathrm{r}=-0,3 ; \mathrm{p}=0.02)$, and $120 \mathrm{~s}(\mathrm{r}=-0,4 ; \mathrm{p}=0.03)$, after the injection of fentanyl. Administration of etomidate resulted in a significant (negative) correlation between the ESG difference values (DESG $\left(t_{x}\right)$ ) and the BIS values at the measurement time points of $0 \mathrm{~s}(\mathrm{r}=-0,3 ; \mathrm{p}=0.03), 20 \mathrm{~s}(\mathrm{r}$ $=-0,3 ; \mathrm{p}=0.03)$ and $40 \mathrm{~s}(\mathrm{r}=-0,4 ; \mathrm{p}=0.02)$.

Baseline skin impedances varied greatly among study participants. This provides the explanation for the broad spread among the ESG values. Generally, the skin impedances rose after injection of fentanyl, and BIS values decreased. After etomidate administration, the skin impedances took a steep increase whereas the BIS values underwent a considerable fall. The paired t-test revealed highly significant changes both for the ESG difference values (DESG $\left(t_{x}\right)$ and for the BIS values $(p<0.001)$ in a direct comparison of the individual time intervals following administration of fentanyl and etomidate. See blood pressure, BIS and ESG original curves of a patient during induction of anaesthesia (Fig. 5).

\section{Discussion}

The results of this study show the course of skin impedances measured by the ESG during induction of cardiosurgical anaesthesia with fentanyl and etomidate. Fentanyl bolus injection, and particularly the additional etomidate bolus injection, produced a noteable change in skin impedance over the whole clinical course. Skin impedances measured with the ESG showed a significant correlation with the bispectral index values at individual measurement time points. Many nonanesthetic factors affecting the EEG [13]. Interpretation of the raw EEG is dependent on the experience of the electroencephalographer. But with an EEG sedative effects of different agents can be monitored $[14,15]$.

For this study to also assess the effect produced by fentanyl and etomidate, EEGs were administered using BIS monitoring in addition to the skin impedance measurements. Although detailed information regarding the computation algorithms used [16] are still to be provided by the manufacturer, bispectral EEG analysis is deemed to be the most established EEG procedure for predicting anaesthetic depth $[17,18]$.

Many studies were able to demonstrate that the BIS offers a reliable measure of sedation during general anaesthesia $[19,20]$. The weak points of this method lie in the fundamental difficulty the EEG has in recording the subcortical activities during general anaesthesia. During a sevofluran anaesthesia, Katoh and colleagues found an insufficient prediction reliability of several EEG parameters with respect to patients movements in response to skin incision [21]. Another point is that also the effects of nitrous oxide, ketamine and opiates cannot be computed with the help of the BIS during general anaesthesia [22]. In a multicenter study involving 304 patients, Sebel and colleagues found that the BIS provides an insufficient prediction reliability regarding patients movements in response to skin incision in opiate-supplemented anaesthesias [23].

Fentanyl reacts on $\mu 1, \mu 2, \delta$, as well as on $\kappa$ receptors. Agonization of the $\kappa$-receptor results in slight sedation. The cortex has a great abundance of $\kappa$-receptors which may reduce electrical activity in the cortex and thus influence the EEG values measured.

The fact that our study found an impact on BIS values after injection of fentanyl can therefore be explained by a fentanyl agonization of the $\kappa$-receptor, but not by an agonization of the receptors $\mu 1, \mu 2, \delta$ that are responsible for analgesia [24]. $\mu$ receptors are located in the substantia gelatinosa of the spinal cord, and supraspinal locations include brainstem and subcortex [25].

The difference between our study and other studies addressing skin conductance measurements [26, 27, $28,29]$ is that we have evaluated the effects upon the impedance of the skin of a bolus dose of fentanyl, given without additional hypnotics. Furthermore, we studied the effects generated by an additional bolus administration of hypnotics to the same patients. Impedance electrodermal response and skin conductance reflect the activity in the skin sympathetic fibers. However, the experimental settings are different. Skin sympathetic reaction is triggered in subcortical and cortical regions of the CNS with input arising from the hypothalamus, the limbic system and the basal ganglia [30]. Sympathetic efferent pathways descending from the hypothalamus run through the brainstem, synapsing with pre-ganglionic neurons in the Nc. intermediolaterales of the lateral horn. The second synapse is in the sympathetic trunk. The post-ganglionic neurites take their path as sympathetic-sudomotor fibers, together with the remaining portions of the peripheral nerves, up to neuroglandular junctions. Sympathetic activation by cortical and subcortical areas $[31,32]$ will therefore result in changes in the target organ, the eccrine sweat glands, that are exclusively innervated by the sympathetic nervous system. There is a direct correlation between the activity of the eccrine sweat glands and the changes in skin resistance [33]. Using the constant current technique, Lidberg and Wallin have proved that there is a direct correlation between the discharge rate of skin sympathetic nerve portions and the amplitude of the simultaneously recorded skin impedance responses [34, 35].

The involvement of cortical structures has certainly interfered with skin impedance measurements under the influence of fentanyl. It is a commonly known fact that also emotions have an influence on the values 
obtained from skin impedance measurements, in addition to manual, visual and acoustic stimuli $[36,37,38]$. It can therefore be assumed that, depending on the vigiliance level [39], emotions, anxieties and acoustic disturbances encountered during induction of anaesthesia for a risk-bearing cardiosurgical intervention counteracted the sedative and vigilance-reducing effect of opiate drugs [40]. The effect of fentanyl upon skin impedance probably would have been even more evident without these cortical influences. An interaction with opiate-induced effects such as nausea, thoracic rigidity, and influence on thermoregulation [41] cannot be excluded. In an intraoperative study involving 11 patients, Storm and colleagues have postulated that the analgesic effect of a general anaesthesia can be determined through measurements of the skin conductance [42]. Geddes and colleagues examined $45 \mathrm{pa}-$ tients preoperatively and found a decrease in skin conductance only after premedication with diazepam, but not after premedication with intramuscular morphine.

In our study we were able to demonstrate that fentanyl has a significant impact on the skin impedance in the absence of additional hypnotics.

The fact that there are great variances in the baseline values of the individual patients poses a problem for the interpreation of skin impedance measurement data; our own data revealed that there were patients whose skin impedance was up to ten times higher than that of others. Skin resistance is also influenced by factors such as skin condition, the measurement electrodes used, and the recording site. This causes the measurement values to spread across a wide range.

\section{CONCLUSION}

Both administration of etomidate and of fentanyl result in direct changes in skin impedance. It appears to be possible to use the ESG for online recording of effects of opiates in general aneasthesia. Using multimodal neuromonitoring setups involving skin impedance measurements and BIS monitoring in order to predict analgesic response and depth of hypnosis (BIS) during general anaesthesia seems to be an option for the future.

Conflict of interest: There exists no conflict of interests.

\section{REFERENCES}

1. Stockham RJ, Stanley TH, Pace NL, King K, Groen F, Gillmor ST. Induction of anesthesia with fentanyl or fentanyl plus etomidate in high-risk patients. J Cardiothorac Anesth. 1987; 1: 19-23.

2. Sahin AS, Duman A, Atalik EK, Ogun CO, Sahin TK, Erol A, Ozergin U. The mechanisms of the direct vascular effects of fentanyl on isolated human saphenous veins in vitro. J Cardiothorac Vasc Anesth. 2005;19:197-200

3. Paris A, Philipp M, Tonner PH, Steinfath M, Lohse M, Scholz J, Hein L. Activation of alpha 2B-adrenoceptors mediates the cardiovascular effects of etomidate. Anesthesiology. 2003; 99: 889-95.

4. Hess WC, Ohe A. Does ketamine/propofol anesthesia possess antiarrhythmogenic quality? A perioperative study in aortocoronary bypass patients. Eur J Med Res. 2001; 6:543-50.
5. Phillips AA, McLean RF, Devitt JH, Harrington EM. Recall of intraoperative events after general anaesthesia and cardiopulmonary bypass. Can J Anaesth. 1993; 40: 922926

6. Rodriguez RA, Edmonds HL Jr, Schroeder JA. Electroencephalogr. Clin Neurophysiol. 1987; 4:250-253.

7. Barr G, Anderson RE, Samuelsson S, Owall A, Jakobsson JG. Fentanyl and midazolam anaesthesia for coronary bypass surgery: a clinical study of bispectral electroencephalogram analysis, drug concentrations and recall. Br J Anaesth. 2000; 84: 749-52.

8. Barr G, Anderson RE, Owall A, Jakobsson JG. Effects on the bispectral index during medium-high dose fentanyl induction with or without propofol supplement. Acta Anaesthesiol Scand. 2000; 44: 807-811.

9. Gjerstad AC, Storm H, Hagen R, Huiku M, Qvigstad E, Raeder J. Comparison of skin conductance with entropy during intubation, titanic stimulation and emergence from general anaesthesia Acta Anaesthesiol Scand. 2007; 51: 815

10. Janitzki A, Föckeler W. A mobile system for signal adaptive data storage-application in physiological measurements. Measurement. 1986; 4: 82-86.

11. Winterhalter M, Schiller J, Münte S, Bund M, Hoy L, Weilbach C, Piepenbrock S, Rahe-Meyer N. Prospective Investigation into the Influence of Various Stressors on Skin Impedance. J Clin Monit Comput. 2008 ; 22:6774

12. Winterhalter M, Münte S, Taschenbrecker $P$, Hecker $H$, Weilbach C, Osthaus AW, Gross M, Piepenbrock S, Rahe-Meyer N. Skin impedance correlates to sedation grade, plasma propofol concentrations and bispectral index during a target-controlled infusion of propofol. Eur J Anaesthesiol. 2009; 26: 589-96

13. Dimpfel W, Wedekind W, Keplinger I. Gender difference in electrical brain activity during presentation of various film excerpts with different emotional content. Eur J Med Res. 2003; 8:192-8

14. Dimpfel W, Suter A. Sleep improving effects of a single dose administration of a valerian/hops fluid extract - a double blind, randomized, placebo-controlled sleep-EEG study in a parallel design using electrohypnograms. Eur J Med Res. 2008; 13:200-4.

15. Muttray A, Kürten R, Jung D, Schicketanz KH, MayerPopken O, Konietzko J. Acute effects of 200 ppm 1,1,1trichloroethane on the human EEG. Eur J Med Res. 2000; 5: 375-84.

16. Rosow C, Manberg PJ. Bispectral index monitoring. Anesthesiol Clin North America. 2001; 19: 947-966

17. Myles PS, Leslie K, McNeil J, Forbes A, Chan MT. Bispectral index monitoring to prevent awareness during anaesthesia: the B-Aware randomised controlled trial. Lancet. 2004; 363: 1757-1763.

18. Lennmarken C, Sandin R. Neuromonitoring for awareness during surgery. Lancet. 2004; 363: 1747-1748.

19. Struys M, Versichelen L, Mortier E, Ryckaert D, De Mey J.C, De Deyne C, Rolly G: Comparison of spontaneous frontal EMG, EEG power spectrum and bispectral index to monitor propofol drug effect and emergence. Acta Anaesthesiol Scand, 1998; 42: 628-636.

20. Glass PS, Bloom M, Kearse L, Rosow C, Sebel P, Manberg P. Bispectral analysis measures sedation and memory effects of propofol, midazolam, isoflurane, and alfentanil in healthy volunteers. Anesthesiology. 1997; 86: 836-847.

21. Katoh T, Suzuki A, Ikeda K. Electroencephalographic derivatives as a tool for predicting the depth of sedation and anesthesia induced by sevoflurane. Anesthesiology. 1998; 88: 642-650.

22. Johansen JW, Sebel PS. Development and clinical application of electroencephalographic bispectrum monitoring. Anesthesiology. 2000; 93: 1336-344. 
23. Sebel PS, Lang E, Rampil IJ, White PF, Cork R, Jopling M, Smith NT, Glass PS, Manberg P. A multicenter study of bispectral electroencephalogram analysis for monitoring anesthetic effect. Anesth Analg. 1997; 84: 891-899.

24. Zubieta JK, Smith YR, Bueller JA, Xu Y, Kilbourn MR, Jewett DM, Meyer CR, Koeppe RA, Stohler CS: Regional mu opioid receptor regulation of sensory and affective dimensions of pain. Science. 2001; 293: 311-315.

25. Zubieta JK, Smith YR, Bueller JA, Xu Y, Kilbourn MR, Jewett DM, Meyer CR, Koeppe RA, Stohler CS. mu-opioid receptor-mediated antinociceptive responses differ in men and women. J Neurosci. 2002; 22: 5100-5107.

26. Gjerstad AC, Storm H, Hagen R, Huiku M, Qvigstad E, Raeder J. Skin conductance or entropy for detection of non-noxious stimulation during different clinical levels of sedation. Acta Anaesthesiol Scand. 2007; 51: 1-7.

27. Geddes SM, Gray WM, Millar K, Asbury AJ Skin conductance responses to auditory stimuli and anticipatory responses before venepuncture in patients premedicated with diazepam or morphine. Br J Anaesth. 1993;71: 512516.

28. Nisbet HI, Norris W, Brown J.Objective measurement of sedation. IV. The measurement and interpretation of electrical changes in the skin. Br J Anaesth. 1967; 39: 798805.

29. Goddard GF. A pilot study of the changes of skin electrical conductance in patients undergoing general anaesthesia and surgery. Anaesthesia. 1982; 37: 408-415.

30. Koss MC, Davison MA, Bernthal PJ. Epinephrine inhibition of the electrodermal response in the cat. Psychopharmacology. 1976; 50: 149-152.

31. Critchley HD, Elliott R, Mathias CJ, Dolan RJ. Neural activity relating to generation and representation of galvanic skin conductance responses: a functional magnetic resonance imaging study. J Neurosci. 2000; 20: 30333040 .

32. Bechara A, Tranel D, Damasio H, Damasio AR. Failure to respond autonomically to anticipated future outcomes following damage to prefrontal cortex. Cereb Cortex 1996; 6: 215-225

33. Price E, Korr I. Relationship between Sweat gland activity and electrical resistance of the skin. J Physiol. 1957; 10: 505-510

34. Lidberg L., Wallin G. Sympathetic Skin Nerve Discharges in relation to Amplitude of Skin Response. Psychophysiology. 1981; 268-270.
35. Wallin G., Blumberg H., Hynnin P. Intraneural stimulation as a method to study sympathetic function in the human skin. Neuroscience Letters 1983; 36: 189-194.

36. Bini G, Hagbarth KE, Hynninen P, Wallin BG. Thermoregulatory and rhythm-generating mechanisms governing the sudomotor and vasoconstrictor outflow in human cutaneous nerves. J Physiol. 1980; 306: 537-52.

37. Lipp O., Siddle D., Dall P. Effects of stimulus modality and task condition on blink startle modification and on electrodermal responses. Psychophysiology. 1998; 35: 452-461.

38. Dettmers Chr., Faust H., Fatepour D., Tackmann W. Der sympathische Hautreflex- physiologische Grundlagen, Normalwerte und klinische Anwendungen. Fortschr. Neurol Psychiat. 1993; 61: 369-377.

39. Liguori.R, Donadio. V, Foschini.E, Di Stasi. V, Plazzi. G, Lugaresi. E, Montagna. P. Sleep stage-related changes in sympathetic sudomoteor and vasomotor skin respones in man. Clin Neurophysiol. 2000; 111: 434-439

40. Becerra L, Harter K, Gonzalez RG, Borsook D. Functional magnetic resonance imaging measures of the effects of morphine on central nervous system circuitry in opioid-naive healthy volunteers. Anesth Analg. 2006;103: 208-216

41. Chen X, McClatchy DB, Geller EB, Tallarida RJ, Adler MW. sThe dynamic relationship between mu and kappa opioid receptors in body temperature regulation. Life Sci. 2005; 78: 329-333.

42. Storm H, Myre K, Rostrup M, Stokland O, Lien MD, Raeder JC. Skin conductance correlates with perioperative stress. Acta Anaesthesiol Scand. 2002; 46: 887-895.

Received: September 3, 2009 / Accepted: October 1, 2009

Address for correspondence:

Michael Winterhalter M.D.

University of Düsseldorf

Dept. of Anaesthesiology

Moorenstr.5

40225 Düsseldorf

Germany

Tel.: $\quad$ +49-21181-17828

E-mail: Michael.Winterhalter@med.uni-duesseldorf.de 